УДК $340 ; 342$

\title{
Е.П. Богданова
}

\section{ИСТОРИКО-ПРАВОВОЕ РАЗВИТИЕ ИНСТИТУТА САМОЗАЩИТЫ В РОССИИ}

Исследуется история становления и развития института самозащиты. Проведен анализ источников права зарубежных стран и России с древних времен до настоящего времени, в которых нашла отражение правовая регламентация исследуемого института. Отмечено, что назначение самозащиты выражается в способности правообладателя самостоятельно воздействовать на правонарушителя предусмотренными законом средствами, с помощью которых могут быть достигнуты пресечение, предотвращение, устранение и восстановление нарушенного права. В разные периоды формирования российской правовой системы наблюдалось постепенное развитие и совершенствование института самозащиты, который получил закрепление и в современном законодательстве страны. В статье рассмотрены различные точки зрения российских ученых на исследуемую проблематику. С учетом дискуссионности отечественных научных исследований в данной области указывается на необходимость дальнейшего теоретического исследования института самозащиты и дальнейшего развития современного законодательства, регламентирующего исследуемый институт.

Ключевые слова: самозащита, самооборона, самоуправство, необходимая оборона, Конституция Российской Федерации, Гражданский кодекс Российской Федерации, Уголовный кодекс РСФСР 1922 года, Уложение о наказаниях уголовных и исправительных 1845 года, Артикул воинский 1715 года, Соборное Уложение 1649 года, Судебник Ивана III, Русская Правда, Псковская судная грамота.

DOI: $10.35634 / 2412-9593-2020-30-1-125-131$

В соответствии со ст. 2 Конституции Российской Федерации человек, его права и свободы являются высшей ценностью, а защита прав и свобод - обязанностью государства ${ }^{1}$. Ведущую роль в государственной защите прав и свобод человека играют судебные органы ${ }^{2}$. Вместе с тем особое место в механизме защиты прав и свобод занимает институт самозащиты.

Самозащита - это институт самостоятельного осуществления защиты нарушенного права без обращения за помощью в органы государственной власти. По мнению М.И. Брагинского и В. В. Витрянского, назначение самозащиты заключается в том, чтобы предусмотренными законом средствами обеспечить пресечение, предотвращение, устранение нарушенного права, его восстановление и (или) компенсацию потерь, которые вызваны нарушением права ${ }^{3}$.

Вопросы теоретического изучения и практического применения самозащиты исследовались учеными в разные периоды становления и развития российской правовой системы. Они нашли отражение в работах М.В. Баглая, М.И. Брагинского, В.В. Витрянского, В.П. Грибанова, А.А. Демиховой, Е.И. Козловой, Л.О. Красавчиковой, Д.И. Майер, Л.И. Носенко, Н.Д. Сергеевского, В.И. Синайского, М.П. Фомиченко, Д.С. Чернявского, И.З. Шагивалеева, А.М. Эрделевского и др.

Однако до настоящего времени институт самозащиты в законодательстве России недостаточно регламентирован. Дискуссионный и многоаспектный характер рассматриваемой проблематики оставляет место для проведения дополнительных исследований вопросов теории самозащиты.

Исследование показало, что институт самозащиты имеет давнюю историю. В первобытные времена защита себя и своего имущества основывалась на принципах кровной мести. В Древнем Вавилоне, Индии и Риме институт самозащиты уже имел законодательную регламентацию. Известный принцип Талиона «око за око, зуб за зуб» действовал, когда имело место посягательство на личность или на имущество правообладателя. В частности, в Законах XII таблиц для обеспечения долга разрешался захват вещи, а также убийство вора, застигнутого на месте преступления (8.12) 4

\footnotetext{
${ }^{1}$ Конституция Российской Федерации (принята всенародным голосованием 12.12.1993) (ред. от 21.07.2014 № 11-ФКЗ) // Собрание законодательства РФ. 2014. № 31. Ст. 4398.

${ }^{2}$ Войтович В.Ю., Мухин А.А. Развитие демократических основ - основное направление становления гражданского общества. // Наука Удмуртии. 2017. № 3(81). С. 35-40; Беркутова Е.А. Войтович В.Ю. Правовой анализ механизма защиты прав и свобод человека и гражданина в Удмуртской Республике //Государственное и муниципальное управление: сборник статей магистрантов. 2018. С. 26-29.

${ }_{3}^{3}$ Брагинский М.И., Витрянский В.В. Договорное право: Общие положения. М., 2015. С. 448.

${ }^{4}$ Хрестоматия по истории государства и права зарубежных стран: учебное пособие / сост. В.Н. Садиков. 2-е изд., перераб. и доп. М.: ТК Велби; Проспект, 2008. С. 66.
} 
Понятие самозащиты нашло свое отражение и в Русской Правде. Так, в целях отмщения допускалось ударить кого-либо палкой, жердью, рукой и пр. Вора можно было даже убить, но только непосредственно при его задержании. Таким образом, Русская Правда не только разрешала самозащиту, но признавала законным и самосуд.

В эпоху средневековья на Руси основными источниками права были Новгородская судная грамота и Псковская судная грамота. На сегодняшний день в сохранившихся экземплярах Новгородской судной грамоты не найдено ни одной нормы, связанной с понятием самозащиты. Согласно Псковской судной грамоте, запрещалось устраивать самосуд. В ней не было упоминаний и о самообороне. Защитить себя можно было, обратившись с жалобой к князю или в судебные органы.

В 1497 г. на Руси был принят еще один кодифицированный правовой акт - Судебник Ивана III, где право на подачу жалобы имели только представители привилегированного сословия. Однако крестьянам, которые были недовольны своим хозяином, разрешалось один раз в год - на Юрьев день переходить от одного владельца к другому, что можно считать некой формой самозащиты средневекового права 5 .

Впервые право на необходимую оборону в законодательстве России было закреплено в XVII в. в Соборном Уложении 1649 г. Согласно ст. 200 - 201 Соборного Уложения, разрешалось убийство с целью самообороны при защите своего дома. При этом оборонявшийся человек обязан был в двух случаях обратиться к окольным или в приказ ${ }^{6}$. Однако в Соборном Уложении не были прописаны пределы и конкретные способы самозащиты. Это позволяет полагать, что нарушенное право можно было защищать с применением особой жестокости или даже убийства.

В 1715 г. вступил в силу Артикул воинский, в котором ст. 157 была посвящена самообороне и разрешала убийство нападающего. Однако обороняющееся лицо, которое превысило пределы самообороны, должно было отвечать перед судом за свои действия. Наказанием в этом случае являлось тюремное заключение либо назначение штрафа (ст. 158) ${ }^{7}$.

Еще одним нормативным актом, внесшим вклад в развитие института самозащиты, стало Уложение о наказаниях уголовных и исправительных, принятое в 1845 г. В ст. 98, 107-109 указанного акта содержались нормы о самозащите, предусматривающие необходимую оборону и определяющие её пределы. При этом законодательно были заметно расширены объекты защиты. Нанесение вреда при необходимой обороне не являлось наказуемым. Впервые в законодательстве была регламентирована возможность использования самообороны для защиты других лиц, которые находились в опасном положении 8 .

В 1903 г. было принято Уголовное уложение, ст. 45 и 46 которого были посвящены необходимой обороне и крайней необходимости. Правом на необходимую оборону обладало лицо с целью спасения собственной жизни или жизни другого лица. Основанием для ее применения выступала опасность, которая возникла вследствие угрозы, незаконного принуждения или иной причины, и при этом отсутствовала возможность предотвращения опасности иным средством9 .

Ученым досоветского периода К.Н. Анненковым было разграничено два понятия «самооборона» и «самоуправство». Самоуправством он считал средство внесудебной защиты гражданских прав, а самооборону - средством защиты права.

По его мнению, к признакам запрещенного самоуправства относились:

- «самовольное изъятие имущества из чужого законного или незаконного владения, либо нарушение владения имуществом, также как законного, так и незаконного;

- изъятие имущества из чужого владения или нарушение владения, когда оно предпринимается в видах осуществления какого-либо действительного или предполагаемого права на это имущество, в силу которого самоуправец полагал, что имущество должно находиться или перейти в его владение» ${ }^{10}$.

\footnotetext{
${ }^{5}$ Памятники русского права. М.,1955. С. 374.

${ }^{6}$ Титов Ю.П. Соборное уложение 1649 г. //Хрестоматия по истории государства и права России. М., 2016. С. 84. ${ }^{7}$ Артикул воинский и краткое содержание процессов 1725 г. // Отечественное законодательство Ч. 1. М., 2017. C. 290.

${ }^{8}$ Развитие русского права в первой половине ХІХ века. М., 2018. С. 165.

${ }^{9}$ Российское законодательство X-XI веков. Т. 9: Законодательство эпохи буржуазно-демократической революции. М., 2017. С. 372.

${ }^{10}$ Анненков К.Н. Самоуправство и самооборона как средства защиты гражданских прав // Журнал уголовного и гражданского права. 1893. Кн. 3. С 560-561.
} 
По мнению К.Н. Аненкова, самоуправство в исключительных случаях могло являться законным. Так, собственнику имения либо временному его владельцу разрешалось задерживать находящихся у него в имении чужих домашних животных, например, скот, птицу, которые могли причинить вред имуществу ${ }^{11}$.

Самообороной он признавал «... акт защиты или отражения даже силой каких бы то ни было посягательств на личность, жилище, или на спокойное обладание и пользование имуществом, производимое все равно - насильно или без насилия, как лично, со стороны лица управомоченного, так и с помощью других людей, или же и самостоятельно этими последними, при наличности того лишь условия, чтобы посягательство было противозаконно» ${ }^{12}$.

Примерами самообороны признавались:

- удаление хозяином из его жилища посторонних лиц, которые отказывались добровольно покинуть его по требованию хозяина;

- самозащита от чужих животных;

- уничтожение или повреждение чужих вещей в имении хозяина, которые создавали угрозу, представляли опасность, наносили вред или препятствовали спокойному владению и пользованию;

- уничтожение преград, мешающих спокойному пользованию имуществом (например, уничтожение выкопанных кем-либо канав с целью ограничения свободного проезда или прохода в имение, или иных преград, препятствующих использованию имущества и проч.).

Исследование показало, что К.Н. Анненков считал «самозащиту» и «самооборону» понятиями синонимами.

Еще одна точка зрения на исследуемую проблему принадлежит Ю. С. Гамбарову, который полагал, что защита права в настоящее время представлена чаще всего судебной защитой, которая осуществляется в формах гражданского процесса. Но независимо от судебной защиты, по его мнению, «мы встречаемся в современном праве со многими формами самоуправства, как "самозащитой"».

В свою очередь В.И. Синайский, например, выделял три института, выражающих внесудебную защиту прав: необходимую оборону, состояние крайней необходимости и дозволенное самоуправство (самопомощь). Дозволенное самоуправство он определял как «право самопомощи, в целях восстановления юридического положения» ${ }^{13}$. По его мнению, в этом случае в отличие от необходимой обороны, речь идет не об охране юридического положения, а именно о его восстановлении. Поэтому самопомощь активна, агрессивна и, как таковая, в особенности строго ограничивается правопорядком. «Самопомощь, - как указывал В.И. Синайский, - допустима в следующих случаях: 1) при невозможности своевременно прибегнуть к власти; и 2) при наличности опасения, что без немедленного вмешательства осуществление притязания станет невозможным или будет значительно затруднено» ${ }^{14}$.

В.И. Синайский отмечал, что современные ему российские законы не признавали дозволенного самоуправства или самопомощи, однако указывал, что «в отдельных случаях признана самопомощь и у нас». Так, например, «по Уставу лесному (ст. 690) разрешалось лесному сторожу задерживать на месте самовольной порубки или иной порчи леса скот, орудия и вещи правонарушителя, а также само лицо, совершившие эти действия. ${ }^{15}$ В.И. Синайский, как и К.Н. Анненков, право удержания строго отличал от дозволенного самоуправства.

В советский период в России самозащита рассматривалась не как институт гражданского права, а как способ предотвращения посягательства на жизнь и регулировалась нормами уголовного и административного законодательства.

В 1922 г. вступил в силу Уголовный кодекс РСФСР, в котором необходимая оборона была закреплена как обстоятельство, исключающее уголовную ответственность. Уже тогда прослеживалась четкость и грамотность формулировок.

В 1958 г. в Основах уголовного законодательства СССР и союзных республик действия, совершенные в состоянии необходимой обороны, не являлись уголовно наказуемыми.

\footnotetext{
${ }^{11}$ См.: Анненков К.Н. Указ. соч. С. 565.

${ }^{12}$ Там же. С. 569.

${ }^{13}$ Синайский В.И. Русское гражданское право. Выпуск І. Издание второе, исправленное и дополненное. Киев, 1917. C. 133.

14 Там же.

${ }^{15}$ Синайский В.И. Указ. соч. С. 134.
} 
Революционным шагом в развитии и становлении института самозащиты в российском законодательстве стала Всеобщая декларация прав и свобод человека и гражданина от 22.11 .1991 г. ${ }^{16}$ Впервые Россия как страна-участник Венской встречи 1986 г. провозгласила право каждого гражданина России защищать свои права и свободы всеми способами, не запрещенными законом и не противоречащими ему. Данные положения получили закрепление и в Основном законе страны - Конституции РФ 1993 г. (ч.2. ст. 45).

В Гражданском кодексе РФ 1996 г. институт самозащиты получил правовую регламентации. Согласно ст. 14 ГК РФ, допускается самозащита гражданских прав. Способы самозащиты должны быть соразмерны нарушению и не выходить за пределы действий, необходимых для его пресечения ${ }^{17}$. Однако данная норма не дает точного определения самозащиты. Действительно, ст.14 ГК РФ указывает только на явный порядок осуществления защиты нарушенных прав, а не на определенный способ этой защиты. По мнению А.П. Сергеева, «...здесь смешаны близкие, но отнюдь не совпадающие понятия способ и форма защиты гражданских прав. Самозащита гражданских прав с позиций теории - это форма их защиты, допускаемая тогда, когда потерпевший располагает возможностями правомерного воздействия на нарушителя, не прибегая помощи судебных или иных правоохранительных органов» ${ }^{18}$.

Для самозащиты характерно то, что субъект гражданского права защищает себя собственными действиями. По сравнению с другими средствами защиты, это защита направлена на саморегулирование нарушенных правовых отношений, без обращения в суд или иной орган, осуществляющий защиту гражданских прав.

Использование данного способа возможно, если соблюдаются следующие условия: а) нарушение права или возможность его нарушения; б) необходимость пресечения нарушения; в) применение мер, которые соответствуют характеру и содержанию правонарушения. Этим условиям отвечает защита прав и интересов собственными силами.

В настоящее время, по мнению Д.А. Шальманова, в основе сущностных характеристик самозащиты как естественного и неотчуждаемого права человека лежит понятие о конституционных ценностях. Во-первых, ценности указывают на рекомендуемое поведение, а не на должное. Право на самозащиту используется только по усмотрению и инициативе самой личности. Оно является способом самореализации индивида. В этом заключается одна из его особых черт. Во-вторых, ценности указывают в качестве правильного то поведение, которое является благом «для меня», которое предпочтительнее. Право на самозащиту направлено на обеспечение индивидуального блага для каждого человека персонально. В-третьих, ценности не регулируют отношения в интересах всех, они должны быть согласованы между собой, и это соглашение будет выражать идентичность данного сообщества ${ }^{19}$.

Исследование показало, что «самозащита» как правовая категория имеет место в гражданском, семейном, административном и уголовном законодательстве, но при этом ведутся дискуссии о содержании ее объекта и предмета.

Так, В.П. Грибанов самозащиту определяет как «совершение управомоченным лицом не запрещенных законом действий фактического порядка, направленных на охрану его личных или имущественных прав и интересов» ${ }^{20}$. С данной формулировкой не согласны Г.А. Свердлык и Э.Л. Страунинг, по мнению которых, самозащита - это допускаемые законом или договором действия управомоченного лица, которые направлены на обеспечение неприкосновенности права, пресечение нарушений и ликвидацию последствий этого нарушения ${ }^{21}$.

\footnotetext{
${ }^{16}$ Всеобщая декларация прав человека (принята Генеральной Ассамблеей ООН 10.12.1948) // Российская газета. 1995.5 апр.

17 Гражданский кодекс Российской Федерации. Ч.1. Федеральный закон от 30.11 .1994 № 51-Ф3 (ред. от 03.08.2018) // Российская газета. 1994. 8 дек.

${ }^{18}$ Гражданское право: учебник. Т. 1. 2-е изд. / под ред. Сергеева А.П. М: Проспект, 2018. С. 67.

${ }^{19}$ Шальманов Д. А., Савенков А.А. К вопросу о самозащите в гражданском праве // Юридическая наука и практика: альманах науч. тр. Самарского юрид. ин-та ФСИН России. 2016. С. 275-277.

${ }^{20}$ Грибанов В.П. Осуществление и защита гражданских прав. Проблемы самозащиты гражданских прав в гражданском праве // Наука и образование: сохраняя прошлое, создаём будущее: сб. ст. Х Междунар. науч.-практ. конф.: в 3 ч. 2017. С. 218-221.

${ }^{21}$ Свердлык Г.А., Страунинг Э.Л. Понятие и юридическая природа самозащиты гражданских прав // Государства и право. 2016. №5. С. 17.
} 
По мнению В. И. Синайского, чем культурнее среда, тем шире должна быть внесудебная защи$\mathrm{Ta}^{22}$. Однако на практике все обстоит по-другому. Отметим, что самозащита семейных прав является важной частью охранительной системы, при этом отсутствие самозащиты не может быть в полной мере компенсировано другими формами защиты. Судебная практика семейных споров, обращаясь к самозащите, не затрагивает определения рассматриваемого понятия.

Важно признать, что самозащиту следует рассматривать как институт, для которого характерны определенные структура средств, способы осуществления защиты прав в случае их нарушения. Что касается самозащиты в семейном праве, то она представляет собой действие, которое совершается при условии нарушения либо угрозы нарушения семейных прав и направлено на лицо, допустившее нарушение права, имеющее целью предупреждение и пресечение нарушения семейных прав. Исследование показало, что самозащита имеет большое значение именно в семейном праве при возникновении алиментных обязательств, в отношениях с участием детей, оставшихся без попечения родителей, а также когда происходит насилие в семье.

В трудовом законодательстве также используется понятие самозащиты. Глава 59 Трудового кодекса РФ посвящена вопросам самозащиты работниками трудовых прав ${ }^{23}$. Согласно ст. 379 указанного кодекса, работник с целью самозащиты своих трудовых прав может отказаться от выполнения работы, которая не предусмотрена трудовым договором, либо если выполняемая работа непосредственно угрожает его жизни и здоровью, известив об этом в письменной форме работодателя или своего непосредственного руководителя либо иного представителя работодателя. В свою очередь ст. 380 ТК РФ запрещает работодателю препятствовать работнику в осуществлении им самозащиты трудовых прав.

Применение самозащиты права связанно с рядом ограничений, предусмотренных в гражданском законодательстве. Согласно ст. 14 Гражданского кодекса РФ, самозащита допускается в случаях, когда её способы соразмерны нарушению и не выходят за пределы действий, которые были бы необходимы для пресечения данного нарушения. Так, примером самозащиты может служить удержание как способ обеспечения обязательства. Согласно п. 9 постановления Пленума Верховного Суда РФ и Высшего Арбитражного Суда РФ от 01.07.1996 № 6/8 «О некоторых вопросах, связанных с применением части первой Гражданского кодекса Российской Федерации», при разрешении вопросов, связанных с самозащитой права, следует учитывать, что самозащита не признается правомерной, если она явно не соответствует способу и характеру нарушений права, и причинённый в процессе самозащиты вред куда более серьёзный, чем предотвращённый ${ }^{24}$. Соразмерность определяется судами, однако они, как правило, не дают разъяснения по поводу конкретных обстоятельств, а лишь делают выводы о соразмерности.

Законодательно установлено, что действия обладателя права в защиту личных и имущественных прав не признаются противоправными, если они совершены в состоянии необходимой обороны. Согласно ст. 37 Уголовного кодекса РФ, необходимая оборона предполагает самозащиту личности и прав обороняющегося от общественно опасного посягательства. Наличие в законе нормы о необходимой обороне содействует предотвращению насильственных посягательств: лицо, намеревающееся совершить преступление, знает, что оно может встретить активное противодействие и что закон считает это противодействие, равно как и причинение вреда нападающему, правомерным. Необходимая оборона дает право гражданину на отражение общественно опасного посягательства. Согласно ст. 1066 ГК РФ, вред, причиненный при самозащите в состоянии необходимой обороны без превышения ее пределов, не подлежит возмещению. Возможно применение мер самозащиты и в состоянии крайней необходимости, которую ст. 1067 ГК РФ трактует как опасность, угрожающую самому обладателю прав или другим лицам, если эта опасность при данных обстоятельствах не могла быть устранена иными средствами. Такие действия, как и действия в состоянии необходимой обороны ГК РФ не признает противоправными. Если в состоянии крайней необходимости причинен вред, то он, как правило, подлежит возмещению. Самозащитой действия в состоянии крайней необходимости могут признаваться, если ценность защищенных прав превышает причиненный вред.

\footnotetext{
${ }^{22}$ Синайский В.И. Русское гражданское право. Вып. І. 2-е изд., испр. и доп. Киев, 1917. С. 133.

${ }^{23}$ Трудовой кодекс Российской Федерации от 30.12.2001 № 197-Ф3 (ред. от 11.10.2018) // Российская газета. 2001. 31 дек.

${ }^{24} \mathrm{O}$ некоторых вопросах, связанных с применением части первой Гражданского кодекса Российской Федерации: Постановление Пленума Верховного Суда РФ № 6, Пленума ВАС РФ № 8 от 01.07.1996 (ред. от 24.03.2016) // Российская газета. 1996. 13 авг.
} 
Постановлением Пленума Верховного Суда РФ от 26.01.2010 № 1 «О применении судами гражданского законодательства, регулирующего отношения по обязательствам вследствие причинения вреда жизни или здоровью гражданина» закреплено, что при причинении вреда в состоянии необходимой обороны (ст. 1066 ГК РФ) вред возмещается на общих основаниях (ст. 1064 ГК РФ) только в случае превышения ее пределов. Размер возмещения определяется судом в зависимости от степени вины как причинившего вред, так и потерпевшего, действиями которого было вызвано причинение вреда. При этом суд, приняв во внимание имущественное положение лица, причинившего вред, вправе уменьшить подлежащую взысканию сумму (ст. 1083 ГК РФ).

Согласно ст. 1067 ГК РФ, вред, причиненный в состоянии крайней необходимости, должен быть возмещен лицом, причинившим вред. Если при рассмотрении дела будет установлено, что причинитель вреда действовал в состоянии крайней необходимости в целях устранения опасности не только в своих интересах, но и в интересах третьего лица, суд может возложить обязанность возмещения вреда на них обоих по принципу долевой ответственности с учетом обстоятельств, при которых был причинен вред. Суд также вправе частично либо полностью освободить этих лиц или одного из них от обязанности по возмещению вреда. Судебная практика не признает самозащиту правомерной, если она явно не соответствует способу и характеру нарушения и причиненный (возможный) вред является более значительным, чем предотвращенный.

В настоящее время существует необходимость обратить пристальное внимание на понятие самозащиты в области гражданского, семейного, уголовного и трудового права. Анализ норм российского законодательства показывает отсутствие законного определения термина «самозащита», нормы слишком минимизированы, четко не раскрывают ее содержания. Также следует отметить, что самозащита частного права отличается от самозащиты публичного права. Нормы частного права устанавливают возможность выбора, а публичного - четкие границы. И что важно, - самозащита различается по своим свойствам в каждой отрасли.

Таким образом, исследование показало, что целью самозащиты является осуществление и совершенствование механизма обеспечения гарантий реализации прав и свобод человека и гражданина и эффективной защиты в случае их нарушения.

Используя право на самозащиту, гражданин вправе самостоятельно быстро и эффективно реагировать на нарушения его прав и обеспечивать их защиту. Вместе с тем существующие пробелы отечественного законодательства, начиная с отсутствия легального определения самозащиты до возникновения трудностей применения ее на практике, требуют его дальнейшего развития и совершенствования.

Поступила в редакцию 20.12.2019

Богданова Елена Петровна, кандидат юридических наук, заведующий кафедрой государственно-правовых дисциплин Ижевский институт (филиал) Всероссийского государственного университета юстиции (РПА Минюста России) 426052, Россия, г. Ижевск, ул. Заречное шоссе, 23

E-mail: kafgpd2@mail.ru

\section{E.P. Bogdanova HISTORICAL AND LEGAL DEVELOPMENT OF THE INSTITUTION OF SELF-DEFENSE IN RUSSIA}

DOI: $10.35634 / 2412-9593-2020-30-1-125-131$

The article is devoted to the study of the history of formation and development of the institution of self-defense. The analysis of the sources of law of foreign countries and Russia from ancient times to the present, which reflect the legal regulation of the institution under study, has been carried out. It is noted that the purpose of self-defense is expressed in the ability of a right holder to independently influence the offender by the means prescribed by law, with the help of which the suppression, prevention, elimination and restoration of the violated right can be achieved. In different periods of the Russian legal system formation, a gradual development and improvement of the institution of self-defense was observed, which was also enshrined in modern legislation of the country. The article discusses the various points of view of Russian scientists on the studied issues. Given the debatability of domestic scientific research in this area, the need for further theoretical research of the institution of self-defense is noted, taking into account the results obtained by 
scientists at different time periods. The need for further development of modern legislation governing the institution under study is also noted.

Keywords: self-defense, self-protection, arbitrariness, necessary defense, Constitution of the Russian Federation, Civil Code of the Russian Federation, Criminal Code of the RSFSR of 1922, Code of Criminal and Correctional Penalties of 1845, Military Code of 1715, Cathedral Code of 1649, Judicial Code of Ivan III, Russian Truth, Pskov Judicial Certificate.

Bogdanova E.P., Candidate of Law, Head of the Department of State Law Disciplines Izhevsk Institute (branch) of the All-Russian State University of Justice (RPA of the Ministry of Justice of Russia)

Zarechnoe shosse st., 23, Izhevsk, Russia, 426052

E-mail: kafgpd2@mail.ru 